\title{
Experimental Investigation on Evidence of Low Effect of Hemp Bio-Aggregates on Thermal Property of Hemp Concrete
}

\author{
César Niyigena*, Sofiane Amziane and Alaa Chateauneuf \\ University of Auvergne, France
}

Submission: March 28, 2017; Published: May 04, 2017

*Corresponding author: César Niyigena, University of Auvergne, Institut Pascal, Polytech 'Clermont-Ferrand-63174 AubièreCédex, France, Email: cesar.niyigena@uca.fr; sofiane.amziane@uca.fr; alaa.chateauneuf@uca.fr

Keywords: Hemp bio-aggregates; Hemp concrete; Thermal conductivity; Low impact; Variability

\section{Mini Review}

The impact of Hemp Bio-Aggregates (HBA) on Hemp Concrete (HC) have been treated in previous studies [1-2]. In those studies, used HBA are of limited variability. Moreover, the considered properties are mainly based on particle size and HBA origin. Since many parameters (curing conditions, the specimen size, etc.) are taken into account at the same time, it comes difficult to assess the impact of HBA due to parameter interferences.

The present study focuses on the thermal conductivity variability of $\mathrm{HC}$ due to $\mathrm{HBA}$. The selection procedure for nine HBA has been developed in a previous study [3] in which different characteristics is taken into account. The aim was to predict the imapct of HBA on HC performance. The study revealed three categories of HBA, which are supposed to result in three mechanical performances (high, medium and low) of HC. Thus, it is recommended to conduct tests in order to validate the predicted results. At one hand, results on mechanical performance are consistent with the prediction [4]. At the other hand, result for thermal conductivity are not very impacted by HBA type, they are presented in the herein study. The thermal conductivity was measured by the "hot wire" method illustrated in (Figure 1). Specimens used are the same as for mechanical test [4]. Thus, for a given measurement, two specimen are used (Figure 1), and an average value is considered, (Table 1).

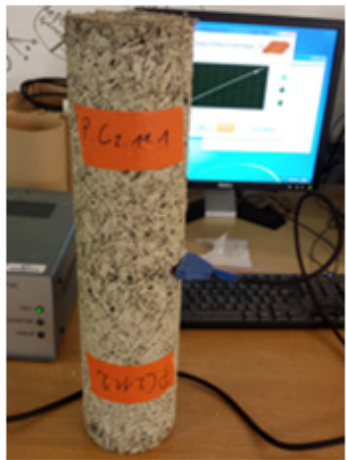

(a) cylinders

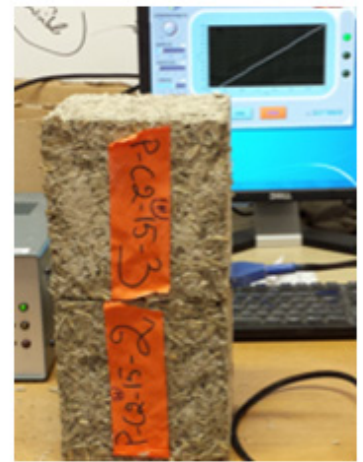

(b) cubes

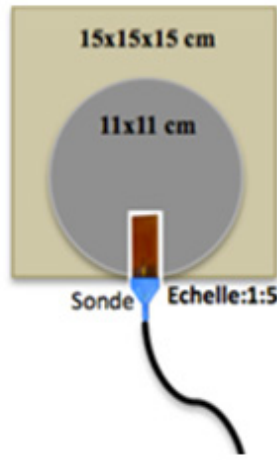

(c) hot wire with contact surfuses

Figure 1: Experimental devices for thermal conductivity test. 
Table 1: thermal conductivity [W/m.K] per HBA, specimen type and direction of heat flux at different ages.

\begin{tabular}{|c|c|c|c|c|c|c|c|c|c|}
\hline & Specimen type & \multicolumn{4}{|c|}{ Cylinder $(11 \times 22 \mathrm{~cm} 2)$} & \multicolumn{4}{|c|}{ cube $(15 \times 15 \times 15 \mathrm{~cm} 3)$} \\
\hline & Age of test (days) & 30 & 60 & 90 & 180 & 30 & & 180 & \\
\hline & Direction & & & & & $\perp$ & // & $\perp$ & // \\
\hline \multirow{9}{*}{$\begin{array}{l}\text { Hemp bio- } \\
\text { aggregates } \\
\text { type }\end{array}$} & C2 & 0.116 & 0.107 & 0.089 & 0.083 & 0.118 & 0.113 & 0.100 & 0.095 \\
\hline & $\mathrm{C4}$ & 0.094 & 0.091 & 0.075 & 0.075 & 0.100 & 0.092 & 0.084 & 0.083 \\
\hline & C5 & 0.124 & 0.110 & 0.089 & 0.087 & 0.124 & 0.111 & 0.103 & 0.094 \\
\hline & C12 & 0.093 & 0.093 & 0.083 & 0.080 & 0.111 & 0.101 & 0.098 & 0.092 \\
\hline & C3 & 0.111 & & & 0.092 & & & & \\
\hline & C6 & 0.119 & & & 0.091 & & & & \\
\hline & C10 & 0.101 & & & 0.087 & & & & \\
\hline & C11 & 0.101 & & & 0.079 & & & & \\
\hline & C13 & 0.096 & & & 0.075 & & & & \\
\hline
\end{tabular}

The thermal conductivity varies according to HBA type, at 30 days a minimum of $0.093 \mathrm{~W} / \mathrm{m} . \mathrm{K}$ and a maximum of $0.124 \mathrm{~W} / \mathrm{m} . \mathrm{K}$ are observed for hemps C12 and C5, respectively. However, it is to note that at 180 days the thermal conductivity decreases below $0.1 \mathrm{w} / \mathrm{m} . \mathrm{K}$. In fact, the more the material dries, the more the water contained in the pores evaporates; these pores are then empty or filled with air, which increases the insulating power of the material. At this age, a minimum of $0.075 \mathrm{~W} / \mathrm{m} . \mathrm{K}$ and a maximum of $0.092 \mathrm{~W} / \mathrm{m}$. Kare observed for HBA C4, C13 and C3, respectively. Moreover, the thermal conductivity may also vary according to the orientation of HBA or the direction of heat flow with respect to the compaction energy, and also the shape of the specimen used. In this latter case, the issue is about the boundary/side effect.

Results show that the thermal conductivity is higher in the direction of heat flow perpendicular to the direction of compaction with values ranging from 0.084 to $0.124 \mathrm{~W} / \mathrm{m}$.K whatever the type of HBA type and age. In the parallel direction, the results vary from 0.083 to $0.113 \mathrm{~W} / \mathrm{m}$.K. For specimen type, the tests are carried out with the heat flux parallel to the direction of compaction, which leads to low thermal conductivity for cylinders. This is due to its rounded shape and small contact area (Figure 1), heat loss is likely to occur, leading to low thermal conductivity.

Results for different HBA show low variability; however, the performed analyses show that the specimen type and direction of heat flux are likely to contribute to observed variability. Hence, further investigations taking into account the specimen type and the protocol may allow bettering understanding this variability and help to fix the standards to be used for the characterization of HC.

\section{References}

1. Arnaud L, Gourlay E (2012) Experimental study of parameters influencing mechanical properties of hemp concretes. Construction and Building Material 28(1): 50-56.

2. Stevulova N, Kidalova L, Cigasova J, Junak J, Sicakova A, et al. (2013) Lightweight composites containing hemp hurds. Procedia Eng 65: 6974.

3. Niyigena C, Amziane S, Chateauneuf A (2015) Etude de la variabilité des caractéristiques de granulats de chanvre. Rencontres Universitaires de Génie Civil, France.

4. Niyigena C, Amziane S, Chateauneuf A (2017) Investigating Hemp Concrete Mechanical Properties Variability Due to Hemp Particles. In: Mechanics of Composite and Multi-functional Materials 7: 9-17.

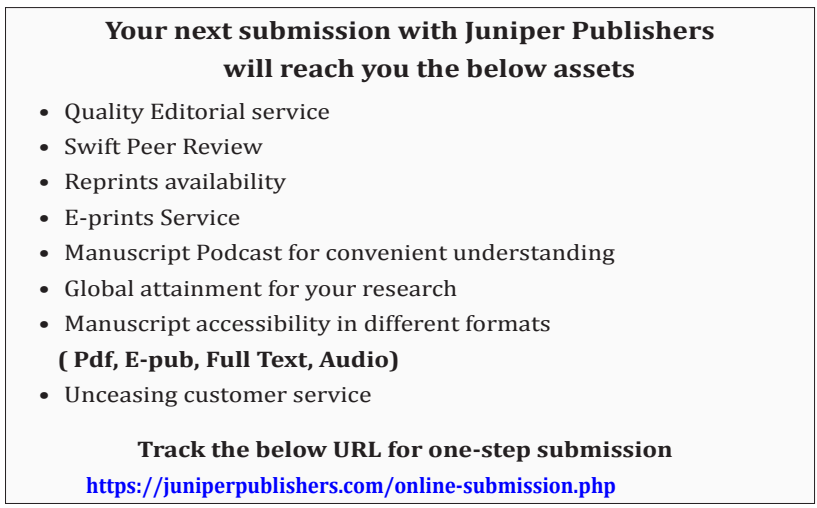

